\title{
Assessment of irrigation physics in a land surface modeling framework using non-traditional and human-practice datasets
}

\author{
Patricia M. Lawston ${ }^{1,2}$, Joseph A. Santanello Jr. ${ }^{2}$, Trenton E. Franz ${ }^{3}$, and Matthew Rodell ${ }^{2}$ \\ ${ }^{1}$ Earth System Science Interdisciplinary Center, University of Maryland, College Park, MD 20740, USA \\ ${ }^{2}$ Hydrological Sciences Laboratory, NASA Goddard Space Flight Center, Greenbelt, MD 20771, USA \\ ${ }^{3}$ School of Natural Resources, University of Nebraska-Lincoln, Lincoln, NE 68583, USA \\ Correspondence to: Patricia M. Lawston (patricia.m.lawston@nasa.gov)
}

Received: 1 February 2017 - Discussion started: 8 February 2017

Revised: 28 April 2017 - Accepted: 7 May 2017 - Published: 16 June 2017

\begin{abstract}
Irrigation increases soil moisture, which in turn controls water and energy fluxes from the land surface to the planetary boundary layer and determines plant stress and productivity. Therefore, developing a realistic representation of irrigation is critical to understanding land-atmosphere interactions in agricultural areas. Irrigation parameterizations are becoming more common in land surface models and are growing in sophistication, but there is difficulty in assessing the realism of these schemes, due to limited observations (e.g., soil moisture, evapotranspiration) and scant reporting of irrigation timing and quantity. This study uses the Noah land surface model run at high resolution within NASA's Land Information System to assess the physics of a sprinkler irrigation simulation scheme and model sensitivity to choice of irrigation intensity and greenness fraction datasets over a small, high-resolution domain in Nebraska. Differences between experiments are small at the interannual scale but become more apparent at seasonal and daily timescales. In addition, this study uses point and gridded soil moisture observations from fixed and roving cosmic-ray neutron probes and co-located human-practice data to evaluate the realism of irrigation amounts and soil moisture impacts simulated by the model. Results show that field-scale heterogeneity resulting from the individual actions of farmers is not captured by the model and the amount of irrigation applied by the model exceeds that applied at the two irrigated fields. However, the seasonal timing of irrigation and soil moisture contrasts between irrigated and non-irrigated areas are simulated well by the model. Overall, the results underscore the necessity of both high-quality meteorological forcing data and proper
\end{abstract}

representation of irrigation for accurate simulation of water and energy states and fluxes over cropland.

\section{Introduction}

Irrigation is vital to feeding the world's population and accounts for $\sim 40 \%$ of global food production and $20 \%$ of arable land (Molden, 2007; Schultz et al., 2005). Approximately $70 \%$ of global freshwater withdrawals (FAO, 2014) are used to meet the demand for irrigation, thereby altering the hydrologic cycle and raising questions about water resources sustainability. As a result, irrigation modeling studies have sought to understand the impacts of irrigation on ambient weather (Sorooshian et al., 2011, 2012), precipitation and streamflow (Harding and Snyder 2012a, b; Kustu et al., 2011), and regional to global climate (Lo and Famiglietti, 2013; Puma and Cook, 2010). Although the atmospheric response is often sensitive to the details of the irrigation scheme used in modeling studies, the observational data needed to fully vet an irrigation scheme (e.g., irrigation timing, practices, and co-located soil moisture) are generally not obtainable in a spatially continuous format at the scale of high-resolution land surface models (LSMs), making robust evaluation difficult and casting doubt on conclusions about downstream impacts on regional weather, precipitation, and long-term climate.

The impact of water resources management practices such as irrigation on the water cycle is significant enough that the World Climate Research Program (WCRP) has identified anthropogenic changes to the continental water cycle as 
a Grand Science Challenge to be addressed over the next 5 to 10 years (Trenberth and Asrar, 2014). In response, the Global Energy and Water Cycle Exchanges project's (GEWEX) Hydroclimatology Panel (GHP) and Global Land/Atmosphere System Study (GLASS) have begun a joint effort to advance the representation of human water resources management in land surface and coupled models (van Oevelen, 2016). To effectively meet these challenges, new, non-traditional datasets are needed to evaluate and improve representation of irrigation in models and to assess the processes by which simulated irrigation impacts the water cycle.

The work presented here touches on each of these issues by comprehensively assessing a sprinkler irrigation algorithm in a LSM and evaluating the results with both conventional and non-traditional datasets. The integration of humanpractice data (i.e., irrigation amount and timing), physical observations (e.g., soil moisture point and spatial observations), and model simulations to evaluate the sprinkler algorithm and its impacts on soil moisture is a key and novel feature of this study. The paper is organized in the following way: Sect. 2 provides relevant background on recent irrigation modeling efforts with an emphasis on differences in irrigation schemes and previous evaluation efforts, and introduces gridded soil moisture from the cosmic-ray neutron probe method (CRNP) as a potential tool for evaluation of land surface model irrigation. A description of the experimental design, including the land surface modeling framework and the irrigation algorithm, is presented in Sect. 3. Section 4 describes the results, first in the context of model sensitivity and then through an evaluation of the model simulations with observations. A discussion of the results and the applicability of this study to future irrigation modeling efforts is presented in Sect. 5, and conclusions are stated in Sect. 6.

\section{Background}

\subsection{Irrigation physics}

Irrigation increases soil moisture and therefore has the potential to influence local and regional clouds, precipitation, and ambient weather via land-planetary boundary layer (PBL) coupling processes (Santanello et al., 2011). By increasing latent heat fluxes and decreasing sensible heat fluxes, nearsurface temperature is reduced within irrigated areas (Bonfils and Lobell, 2007; Kanamaru and Kanamitsu, 2008). The irrigation-modified land energy balance alters the proportion of heat and moisture contributed to the PBL, thereby influencing PBL growth and entrainment (Kueppers and Snyder, 2011; Lawston et al., 2015). As a result, the PBL over irrigated areas is often shallower and moister, potentially resulting in alterations to convective cloud development (Adegoke et al., 2007; Qian et al., 2013). Irrigation applied over large areas not only affects local ambient weather, but models in- dicate that it can also modify precipitation patterns in areas remote from the source (de Vrese et al., 2016), which can further alter streamflow (Kustu et al., 2011). Extensive irrigation projects, such as the Gezira scheme in east Africa, have been shown to influence regional weather by changing circulation and precipitation patterns (Alter et al., 2015).

These significant potential impacts of irrigation on temperature, clouds, precipitation, and related fluxes necessitate an appropriate representation of irrigation in coupled landatmosphere models. This need has been addressed via irrigation parameterizations in LSMs that largely fall into three types of schemes: (1) defined increases to soil moisture in one or more soil layers (Kueppers and Snyder, 2011; de Vrese et al., 2016), sometimes referred to as flood (Evans and Zaitchik, 2008); (2) the addition of water as pseudoprecipitation to mimic sprinkler systems (Ozdogan et al., 2010; Yilmaz et al., 2014); and (3) modifications to vapor fluxes as a proxy for increased evapotranspiration resulting from highly efficient (e.g., drip) irrigation (Douglas et al., 2006; Evans and Zaitchik, 2008). These schemes are generally dependent on parameter input datasets and user-defined thresholds, affording a degree of customization, but also introducing uncertainty and potential error. Model sensitivity to the selection of datasets and thresholds is not trivial, as differences can alter the magnitude of irrigation-induced changes to the water and energy budgets. For example, a flood irrigation parameterization with two different triggering thresholds resulted in up to $80 \mathrm{~W} \mathrm{~m}^{-2}$ difference in average seasonal latent heat flux increase in the US central Great Plains (Lawston et al., 2015). In another case, Vahmani and Hogue (2014) tested several irrigation demand factors and irrigation timing in their urban irrigation module, finding fluxes, runoff, and irrigation water are sensitive to both inputs. Additionally, the same parameterization used in a different model (Kueppers et al., 2008; Tuinenburg et al., 2014) or in the same model but at a different resolution (Sorooshian et al., 2011) has also produced different coupled atmospheric impacts.

\subsection{Evaluation of irrigation in LSMs}

The sensitivity of atmospheric predictions to the details of the irrigation scheme makes it imperative to systematically evaluate irrigation parameterization, datasets, and thresholds in a controlled modeling study to determine the levels of uncertainty in the perturbation and subsequent results. However, datasets required for evaluation, such as irrigation amount, irrigation timing, and co-located continuous soil moisture observations, are not widely available, making it difficult to evaluate irrigation schemes (Kueppers et al., 2007). Modeling studies that have included some assessment of the irrigation scheme have used comparisons to annual water withdrawals for irrigation (Lobell et al., 2009; Pokhrel et al., 2012), outdoor water use (Vahmani and Hogue, 2014), recommended amounts of irrigation (Sorooshian et al., 2011, 
2012), or irrigation water usage reported by the US Geological Survey (Ozdogan et al., 2010). Bulk estimates such as these are often not used for robust evaluation but rather indicate that the simulated results are reasonable.

In some cases, additional analysis of the observations has been successful in converting estimates to quantities usable for comparison. For example, Pei et al. (2016) used a potential evapotranspiration ratio to estimate June, July, and August irrigation usage from USGS yearly county-level estimates in order to validate irrigation amounts in the Weather Research and Forecasting model (WRF)-Noah mosaic coupled model. The study found good agreement between the amounts simulated and that of the modified observations at $30 \mathrm{~km}$ horizontal resolution. In other cases, county- and coarser-resolution irrigation estimates have been used to constrain the irrigation algorithm output. Leng et al. (2013, 2014) calibrated the irrigation scheme in the Community Land Model (CLM) to reproduce irrigation water usage within counties and water resource regions, respectively. Taken together, these studies exhibit recent progress made in irrigation modeling evaluation at regional to continental scales, but the datasets employed are insufficient for evaluation at high resolution and shorter (e.g., season to submonthly) timescales.

As soil moisture is the primary control over fluxes and vegetation health, an evaluation of soil moisture sensitivity to irrigation is equally as important as realistic irrigation estimates. Such evaluation is challenging, as it demands soil moisture observations that are temporally and spatially continuous and at high enough resolution to resolve an irrigation signal. Satellite remote sensing has obvious potential to reach these goals, but retrievals of soil moisture are generally too coarse (i.e., $\sim 25-40 \mathrm{~km}$ spatial resolution) and exhibit limited skill, at best, in detecting an irrigation signal (Kumar et al., 2015). At the other spatial extreme, point observations of soil moisture values are not representative of the larger area average (Entin et al., 2000). The aggregation of these observations into homogeneous, quality-controlled datasets, such as the North American Soil Moisture Database (NASMD; Quiring et al., 2016) and the International Soil Moisture Network (ISMN; https://ismn.geo.tuwien.ac.at/), are promising for LSM evaluation more broadly, but in situ measurements in irrigated fields, needed for irrigation scheme evaluation, are still sparse.

\subsection{Cosmic-ray neutron probe}

A potential solution to fill the gap between point and remote sensing observations of soil moisture is the CRNP method, organized through the Cosmic-Ray Soil Moisture Observing System (COSMOS; Zreda et al., 2012), which has 200 probes operating globally since 2011. CRNP is a new and novel way to obtain high-resolution, semi-continuous soil moisture observations and, as a result, has the potential to advance LSM and irrigation parameterization development.
The CRNP is placed above the ground and measures neutrons produced by cosmic rays in the air and soil over a diameter of $300 \pm 150 \mathrm{~m}$, depending on atmospheric pressure and humidity (see Desilets and Zreda, 2013; Kohli et al., 2015). The theoretical basis for the CRNP method follows that fast neutrons injected into the soil by the CRNP will be slowed more effectively by collisions with hydrogen atoms (present in soil water) than any other element (Visvalingam and Tandy, 1972). Thus, the neutron density measured by the probe is inversely correlated with soil moisture and can be calibrated using local soil samples to an error of less than $0.03 \mathrm{~m}^{3} \mathrm{~m}^{-3}$ (Franz et al., 2012). The result is reliable area average soil water content integrated to a depth of $\sim 20-40 \mathrm{~cm}$, depending on water content, bulk density, and lattice water, available at the same spatial scale as high-resolution LSMs (Franz et al., 2012).

The characteristics of the CRNP, including the noncontact, passive data collection, make the CRNP portable and able to collect data while in motion. Desilets et al. (2010) first used a roving CRNP in Hawaii to obtain transects of soil moisture at highway speeds. More recently, Chrisman and Zreda (2013) and Dong et al. (2014) used the roving CRNP at the mesoscale in Arizona and Oklahoma. Franz et al. (2015) mounted a large CRNP instrument to the bed of a pickup truck and completed roving surveys during the growing season of 2014 in a $12 \times 12 \mathrm{~km}$ area of eastern Nebraska. The instrument collected $\sim 300$ neutron counts every minute and was driven at a maximum speed of $50 \mathrm{~km} \mathrm{~h}^{-1}$, allowing for high-resolution maps to be generated via geostatistical interpolation techniques. The spatial locations of each neutron measurement are given by the midpoint of successive rover locations and together are spatially interpolated via kriging to $250 \mathrm{~m}$ resolution. The surveys were completed every 3-4 days from May to September. In addition, three fixed probes were located inside the domain continuously recording soil moisture. Franz et al. (2015) used the fixed and roving data with a simple merging technique to produce $8 \mathrm{~h}$ soil moisture products at 1,3 , and $12 \mathrm{~km}$ resolutions.

The work presented here uses these data and products gathered and generated in Franz et al. (2015) for the evaluation of a sprinkler irrigation algorithm in a LSM environment, described in Sect. 3. The main goals of this work are first to assess the physics of the simulated sprinkler irrigation and then to evaluate the realism of the irrigation amounts and impacts on soil moisture.

\section{Methods}

\subsection{Models and experimental design}

NASA's Land Information System (LIS; Kumar et al., 2006) is used in this study to assess the performance of the sprinkler irrigation scheme. LIS is a land surface modeling and data assimilation system that allows users to choose from a suite of land surface models which can then be run offline while con- 


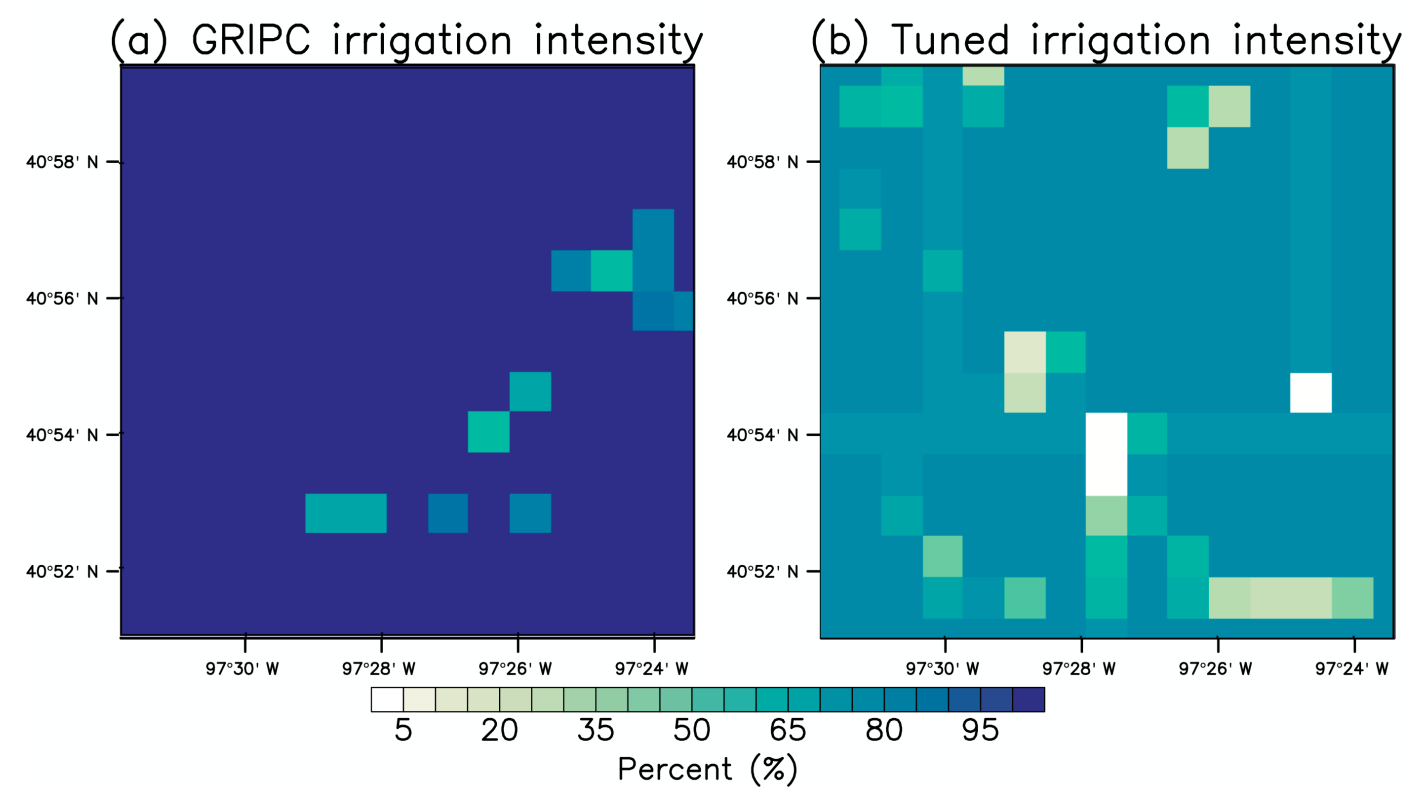

(c) Climatological GVF

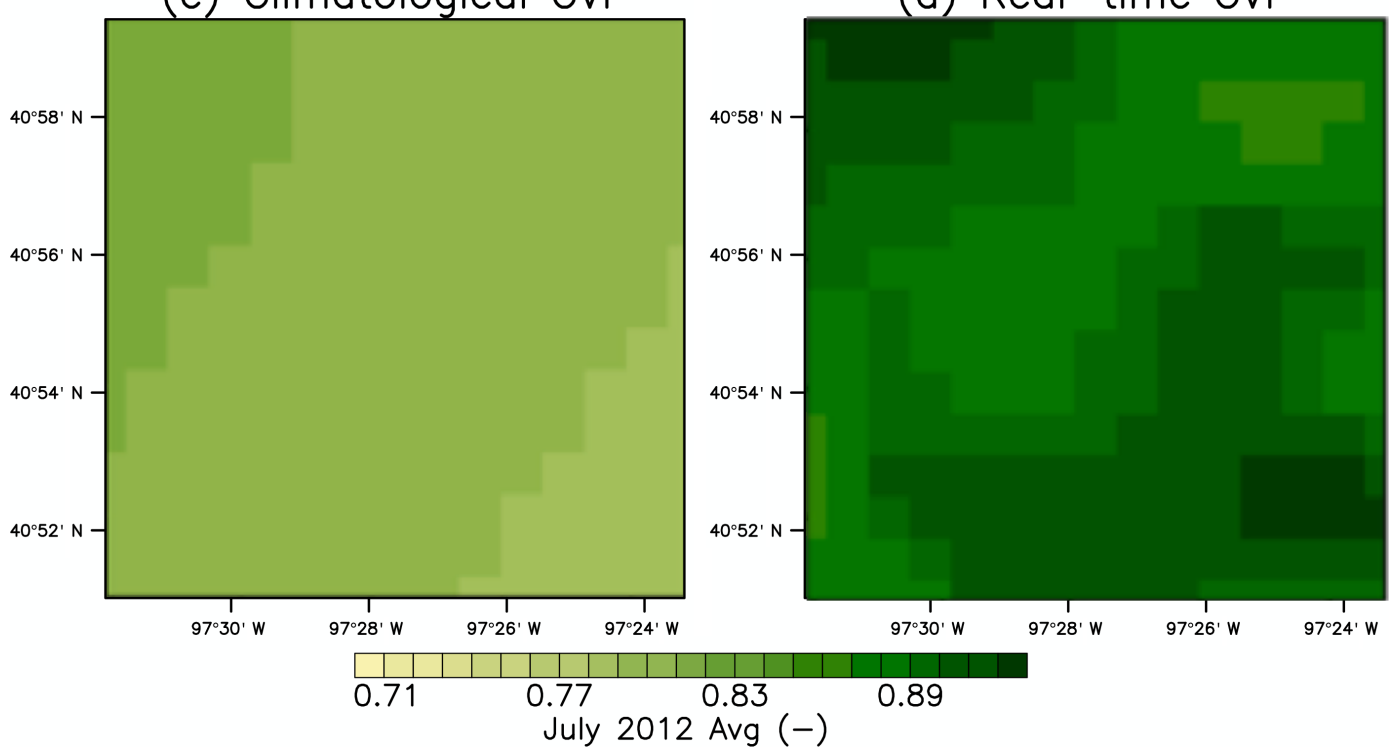

Figure 1. (a) The global rain-fed, irrigated, and paddy croplands dataset (GRIPC) irrigation intensity (percent) given by Salmon et al. (2015) used in the Standard and SPoRT simulations and (b) the observationally tuned irrigation intensity used in the Tuned simulation. The spotty nature of the Tuned simulation indicates where irrigation intensity has been reduce due to the presence of roads, wetlands, rain-fed fields, and/or buildings. Also shown is the average greenness vegetation fraction (unitless) in July 2012 given by (c) NCEP climatology used in the Standard and Tuned simulations and (d) the SPoRT real-time dataset used in the SPoRT run.

strained and forced by the best-available surface and satellite observations. LIS can be fully coupled to the Weather Research and Forecasting model (WRF; Skamarock et al., 2005 ) in the NASA Unified WRF (NU-WRF; Peters-Lidard et al., 2015) framework. This configuration of LIS-WRF has been used at the regional scale to assess the downstream impacts of irrigation on the PBL, but the performance of the irrigation scheme was not assessed (Lawston et al., 2015).
In this study, the Noah land surface model (Chen et al., 2007) version 3.3 was run offline within the LIS framework at $1 \mathrm{~km}$ spatial resolution over a $15 \times 15 \mathrm{~km}$ area in eastern Nebraska, near the town of Waco. The size and location of the domain were designed to encompass the study area of Franz et al. (2015) to make use of the CRNP rover data, human-practice information, and point and spatial observations produced by their work, as discussed in Sect. 2. 
The LIS simulations were run for 6 years (1 January 2009 to 31 December 2014), yielding daily output. The longterm simulation output was used to initialize restart simulations for the growing seasons of 2012 and 2014 to produce hourly output for more detailed investigation during these periods, and the 3- to 5-year spinup periods, respectively, were shown to be sufficient for this region (Lawston et al., 2015). The analysis focuses on these two years (i.e., 2012 and 2014) to evaluate the irrigation algorithm during contrasting antecedent soil moisture conditions (e.g., relatively dry and wet, respectively) and to assess the performance of the scheme using the CRNP observations available in 2014.

To capitalize on the controlled nature of the study area and the irrigation scheme's dependence on green vegetation fraction (GVF) and irrigation intensity, discussed in detail in Sect. 3.3, four types of simulations were completed and will hereafter be referred to as the (1) Control, (2) Standard, (3) Tuned, and (4) SPoRT simulations. The Control run is the only simulation that has the irrigation scheme turned off. The Standard simulation differs from Control only in that the sprinkler irrigation scheme is turned on and the global rainfed, irrigated, and paddy croplands dataset (GRIPC; Salmon et al., 2015) is used to prescribe irrigation intensity at $1 \mathrm{~km}$ resolution needed for the sprinkler algorithm. The Tuned simulation uses an edited irrigation intensity map, described in more detail below, rather than GRIPC. The SPoRT run makes use of the GRIPC irrigation intensity dataset, like the Standard run, but uses a real-time GVF product at $3 \mathrm{~km}$ spatial resolution from NASA-Marshall's Short-term Prediction Research and Transition Center (SPoRT; Case et al., 2014). This is in contrast to the other runs that use climatological GVF at $1 \mathrm{~km}$ from the National Centers for Environmental Prediction (NCEP). Additional datasets common to all simulations include the Moderate Resolution Imaging Spectroradiometer (MODIS) - International Geosphere Biosphere Program (MODIS-IGBP) land cover at $1 \mathrm{~km}$, State Soil Geographic (STATSGO) soil texture at $1 \mathrm{~km}$, University of Maryland (UMD) crop type at $1 \mathrm{~km}$, and National Land Data Assimilation System - Phase 2 (NLDAS-2; Xia et al., 2012) meteorological forcing at $1 / 8^{\circ}(\sim 12 \mathrm{~km})$ which includes bias-corrected radiation and gauge-based precipitation.

The GRIPC irrigation intensity dataset, used in the Standard and SPoRT simulations, integrates remote sensing, gridded climate datasets, and responses from national and subnational surveys to estimate global irrigated area. The dataset closely agrees $(96 \%$ at $500 \mathrm{~m}$ ) with the USGS MIrADUS2007 irrigation dataset (Pervez and Brown, 2010) and an assessment of the GRIPC dataset against field-level inventory data showed an $84 \%$ agreement in Nebraska (Salmon et al., 2015). This dataset represents a significant improvement in defining irrigated areas as compared to previous configurations of this model and scheme (Lawston et al., 2015) in which irrigated areas were defined using the 24category USGS land cover classification, based on data from the 1990s. However, the GRIPC dataset overestimates irriga- tion intensity in the study area, as evidenced by only $5 \%$ of the grid cells having intensity less than $100 \%$ (Fig. 1a). To correct for this overestimation, the Tuned simulation uses an irrigation intensity map created by reducing the GRIPC irrigation intensity according to a land use map generated from ground truth observations (Franz et al., 2015), thereby more accurately reflecting irrigation patterns in the study area (i.e., observationally tuned; Fig. 1b). The SPoRT GVF, used only in the SPoRT simulation, is created using the normalized difference vegetation index (NDVI) from the MODIS onboard the Terra and Aqua satellites and as such reflects the vegetation response to temperature and precipitation. In this way, the SPoRT GVF dataset captures interannual variability in vegetation that is missed by the climatological GVF (Fig. 2). Additionally, SPoRT GVF has been shown to improve the simulated evolution of precipitation in a severe weather event as compared to GVF from climatology when using LIS coupled to a numerical weather prediction model (Case et al., 2014). The use of the SPoRT GVF dataset can be viewed as a middle-of-the-road approach between a simple representation of vegetation (e.g., climatology) and more sophisticated but computationally expensive methods, such as dynamic vegetation or crop growth models (e.g., Harding et al., 2015; Lu et al., 2015). As the SPoRT dataset is not available prior to 2010, the long-term SPoRT simulation uses climatological GVF for 2009-2010, and the SPoRT GVF dataset is incorporated in December 2010 and used throughout the rest of the simulation.

\subsection{Evaluation data}

The non-traditional CRNP soil moisture data products and human-practice data gathered in Franz et al. (2015) are used to evaluate the sprinkler irrigation algorithm in LIS. Humanpractice data in the form of the irrigation amount and dates of irrigation application at one irrigated soybean and one irrigated maize site were reported via personal communication to Franz et al. (2015). These two irrigated sites are also equipped with stationary CRNP probes that continuously monitored soil moisture throughout the growing season of 2014. A third CRNP stationary probe was located in a rain-fed field of mixed soybean and maize. Collectively, these data will be used to evaluate the impact of irrigation on soil moisture dynamics and the ability of the model to reproduce these impacts at the irrigated sites. In addition, precipitation data from the nearby York, Nebraska, Automated Weather Data Network (AWDN), operated by the High Plains Regional Climate Center (HPCC; http://www. hprcc.unl.edu/index.php) are used to understand the background regime leading to the irrigation timing.

Additional non-traditional data from Franz et al. (2015) include a soil moisture product that uses the spatiotemporal statistics of the observed soil moisture fields, as obtained via the CRNP rover surveys, and a spatial regression technique to create a $1 \mathrm{~km}, 8 \mathrm{~h}$ gridded soil moisture product for the grow- 


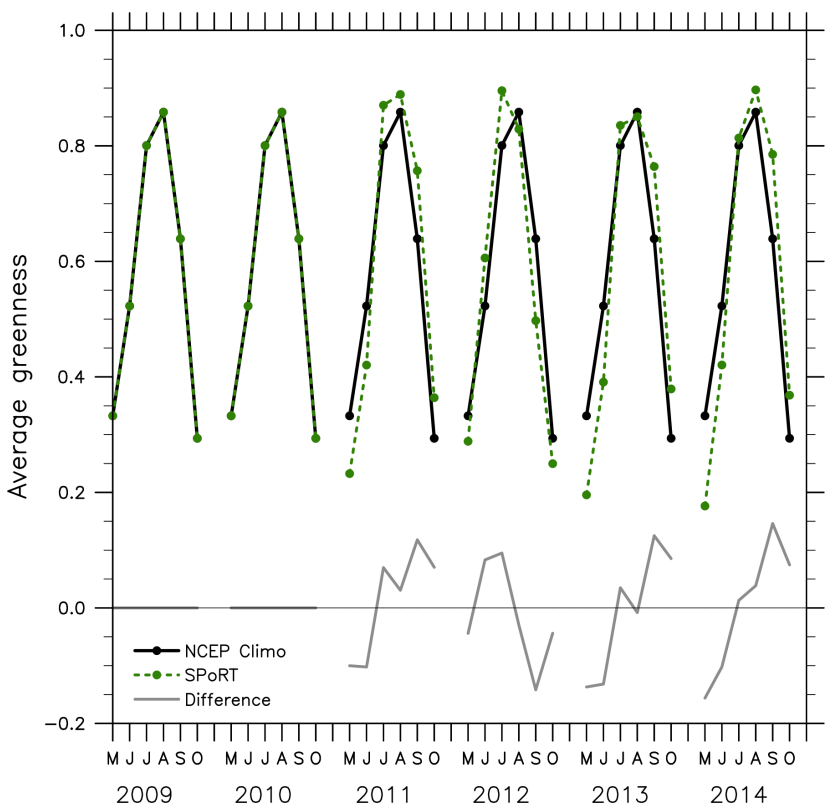

Figure 2. Domain and monthly averaged GVF from the NCEP climatological GVF dataset used in the Standard run, the SPoRT GVF dataset used in the SPoRT run, and the difference between the two (SPoRT - climatology). As the SPoRT dataset is not available prior to 2010, the long-term SPoRT simulation uses climatological GVF for 2009-2010, and the SPoRT GVF dataset is incorporated in December 2010 and used throughout the rest of the simulation.

ing season (May-September, 388 values). Franz et al. (2015) used the average of the three stationary CRNP probes as the regression coefficient, which can smear the spatial differences between irrigated and rain-fed areas. In this study, we modified the spatial regression technique to treat irrigated and non-irrigated areas differently by using the CRNP rainfed probe in the regression for non-irrigated grid cells and the average of the two irrigated CRNP probes for the irrigated grid cells. This results in a gridded soil moisture product that retains the spatiotemporal differences of the rain-fed and irrigated areas. Irrigated and non-irrigated grid cells are defined by an estimated irrigation mask created using the land cover map of Franz et al. 2015 from ground observations. A comparison of the original and new regression products at an irrigated and non-irrigated point is given in the Supplement.

\subsection{Irrigation scheme}

The preferred method of irrigation in Nebraska is the center pivot sprinkler system (NASS, 2014), and as such, we evaluate the sprinkler irrigation algorithm in LIS. The sprinkler scheme is described in Ozdogan et al. (2010) and was preliminarily tested and compared against two other irrigation schemes (drip and flood) available in LIS in Lawston et al. (2015). The sprinkler applies irrigation as precipitation when the root-zone moisture availability falls below a user-

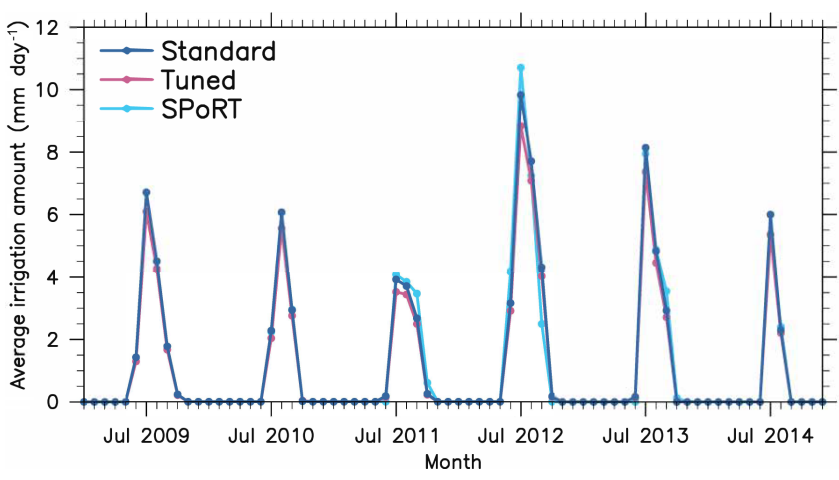

Figure 3. Domain and monthly averaged irrigation amount for each irrigation simulation.

defined threshold. In this study, we use a threshold of $50 \%$ of the field capacity, after Ozdogan et al. (2010).

In an effort to reproduce appropriate timing and placement of irrigation, a series of model checkpoints must be passed to allow for irrigation triggering. These checkpoints essentially boil down to four main questions:

1. Is the land cover irrigable?

2. Is there at least some irrigated land?

3. Is it the growing season?

4. Is the soil in the root zone dry enough to require irrigation?

The first two questions invoke direct tests against the static datasets (land cover and irrigation intensity, respectively), while the remaining two questions require additional calculations involving one or more time-varying datasets. The growing season, addressed in the third question, is a function of the grid-cell GVF (i.e., > $40 \%$ annual range in climatological GVF; Ozdogan et al., 2010) and results in a season that spans roughly June through September in the study area. The last question, the determination of irrigation requirement, is dependent on two main features - the soil moisture and the definition of the root zone. Soil moisture is influenced by the meteorological forcing (e.g., how much rain falls and where) and soil texture (e.g., how long the moisture sticks around), while the root zone is the product of the maximum root depth (as defined by crop type) scaled by the GVF to mimic a seasonal cycle of root growth. Taken together, this means that the irrigation scheme is primarily controlled by six datasets: land cover, irrigation intensity, soil texture, crop type, meteorological forcing, and GVF.

For this limited study area, the land cover, crop type, and soil texture are homogenous throughout the domain as given by the input datasets (croplands, maize, and silt loam, respectively), meaning any heterogeneity in irrigation amounts and impacts can be attributed to only the meteorological forcing, GVF, and irrigation intensity. As the meteorological forcing 
is the same for all simulations, the experimental design leverages the unique characteristics of the controlled domain to assess the sensitivity of the irrigation algorithm specifically to changes in irrigation intensity and GVF, two important and common datasets in irrigation modeling. The irrigation algorithm is assessed first in the context of its physical response to forcing at the interannual, seasonal, and daily scales, and secondly, the results are evaluated against available observations in the growing season of 2014 (i.e., model performance).

\section{Results}

\subsection{Model sensitivity at the interannual scale}

Figure 3 shows the domain and monthly averaged irrigation amount applied for each of the three irrigation runs over the full 6-year period. Interannual variability in the background precipitation (i.e., summer drought or pluvial periods) is reflected in the irrigation requirement, with dry seasons, such as 2012, exhibiting large irrigation demand, while wet seasons like 2011 and 2014 result in markedly less water applied. The average irrigation amount varies little between the experiments at this scale (around $1 \mathrm{~mm} \mathrm{day}^{-1}$ ), but a few features of the dataset differences are apparent. The irrigation algorithm scales the amount of water applied by multiplying with the irrigation fraction value. The GRIPC irrigation dataset has greater irrigation intensity values everywhere in the domain, and as a result, the Standard run always applies more water than Tuned. The SPoRT run is less consistent in relation to the other methods, at times applying more water than both methods (e.g., July 2012), and at others applying less (e.g., September 2012). This behavior is determined by the relative magnitude of the SPoRT GVF as compared to climatological GVF (Fig. 2), as the GVF scales the root zone such that more water is applied by the irrigation scheme to more mature crops.

Figure 4 shows the percent change from Control in soil moisture for each of the irrigation runs and each model soil layer. Irrigation increases soil moisture in all soil layers and all simulations. Increases in the third soil layer, which includes the root zone, are quite consistent annually with a near doubling of the soil moisture when irrigation is turned on. The top and second layer fluctuations resemble the irrigation amount time series, indicating that the top two layers are more sensitive to the amount of irrigation water applied. These layers respond more quickly to irrigation, while percolation, and therefore time, is needed to impact the deeper soil layers. Differences between the irrigation runs are virtually undetectable in the top and second layers, but the cumulative impact of the differences in irrigation amounts and timing are reflected in differences in the third soil layer. The third and fourth layers are deeper and thicker $(0.6$ and $1.0 \mathrm{~m}$ thickness, respectively) and as such are able to hold more water than the top and second layers (0.1 and $0.3 \mathrm{~m}$ thickness).

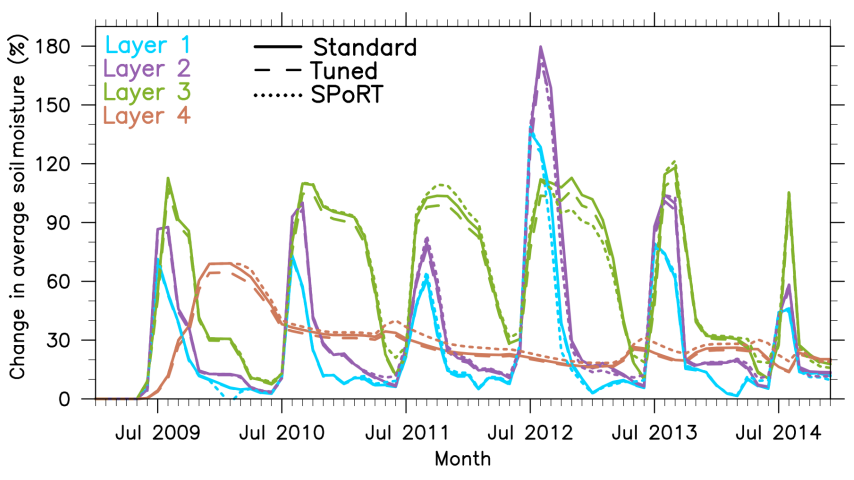

Figure 4. Change from Control (irrigation runs - Control) in soil moisture for each experiment (line style) and each layer (line color). Layer designations are the Noah LSM default layers: layer 1 (top layer) is 0 to $10 \mathrm{~cm}$ depth $(\delta Z=10 \mathrm{~cm})$, layer 2 is 10 to $40 \mathrm{~cm}$ (delta $Z=30 \mathrm{~cm})$, layer 3 is $40 \mathrm{~cm}$ to $1 \mathrm{~m}(\delta Z=60 \mathrm{~cm})$, and layer 4 is 1 to $2 \mathrm{~m}(\delta Z=100 \mathrm{~cm})$.

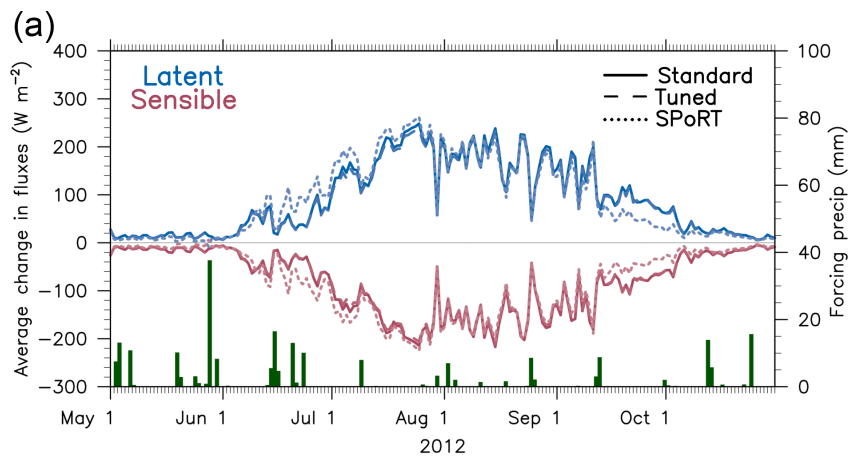

(b)

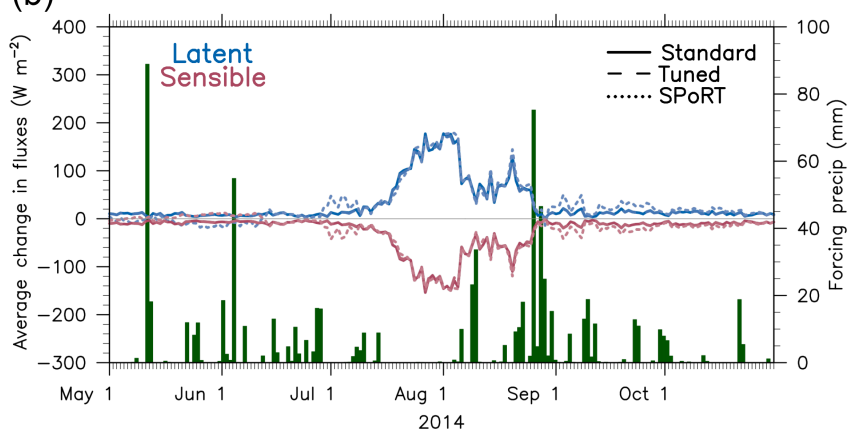

Figure 5. May to September domain average daily change (i.e., irrigation runs - Control) in latent (blue) and sensible (red) heat fluxes (left axis) for (a) 2012 and (b) 2014. Also shown is the domain average daily precipitation from the NLDAS-2 forcing data (right axis).

\subsection{Model sensitivity at the seasonal scale}

Figure 5 shows the average daily change from Control in latent (Qle) and sensible (Qh) heat fluxes (left axis) as well as the daily precipitation amount from the NLDAS-2 meteorological forcing data (right axis) for May-October 2012 and 2014. Limited rainfall throughout the 2012 season re- 
sulted in the triggering of irrigation frequently throughout the growing season, including a stretch through July and August where irrigation was triggered somewhere in the domain every day (not shown). The 2014 growing season featured much more frequent precipitation, limiting consistent irrigation to late July and early August. The flux impacts follow the timing of irrigation triggering, steadily growing throughout the summer in 2012 , up to $200 \mathrm{~W} \mathrm{~m}^{-2}$, and emerging during dry-down periods in 2014. Sharp decreases in flux impacts in the time series are the result of individual precipitation events, as the soil is not dry enough to trigger irrigation during and immediately following heavy rainfall events. In 2012, the SPoRT GVF is greater than climatological GVF in June, resulting in more water applied and greater flux impacts in SPoRT than Tuned or Standard early in the season. However, in September, the SPoRT GVF detects the vegetation stress caused by a July flash drought, resulting in reduced GVF, irrigation amounts, and flux impacts. These seasonal scale impacts illustrate that the NLDAS-2 forcing (i.e., precipitation) data, via changes to soil moisture, constrains the irrigation timing during the growing season, and that the soil moisture threshold is sufficient in triggering irrigation during rain-free periods.

\subsection{Model sensitivity at the diurnal scale}

At the interannual and seasonal scales, irrigation amounts and impacts are driven primarily by background rainfall regime, given by the forcing precipitation, with only small changes evident between the methods. At the diurnal scale, however, the choice of greenness and irrigation intensity datasets becomes more influential to irrigation impacts. Figure 6 shows the change from Control in domain average latent heat flux for each of the irrigation runs for three diurnal cycles in July 2012 and the differences from Control in latent heat flux at noon, spatially. All irrigation runs result in large increases to the latent heat flux, but while Tuned and Standard are relatively close in magnitude, latent heat flux in the SPoRT run is more than $100 \mathrm{~W} \mathrm{~m}^{-2}$ greater than Standard during peak heating. Spatially, the SPoRT simulation has a larger change from Control everywhere in the domain as compared to Standard and Tuned, which exhibit similar magnitude of differences and spatial heterogeneity. The impacts on surface fluxes indicate that the choice of dataset, especially GVF, will likely impact coupled simulations, such as those with LIS-WRF.

In summary, the land cover, GVF, soil texture, meteorological forcing, irrigation fraction, and crop type all influence irrigation amounts in ways that are physically consistent with expectations for crop water use. For example, it is expected that the irrigation requirement is greatest for densely irrigated areas of mature crops with dry soil; the model reproduces this scenario by applying the greatest amount of water to grid cells that have high GVF (i.e., more mature crops and

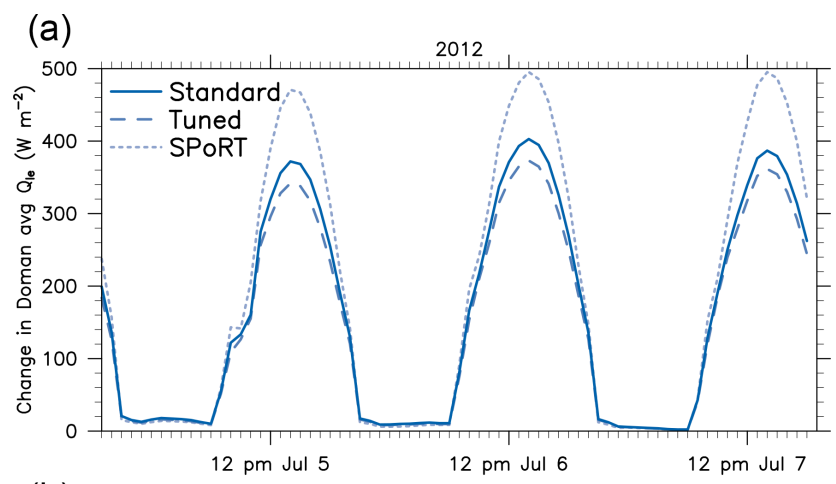

(b)

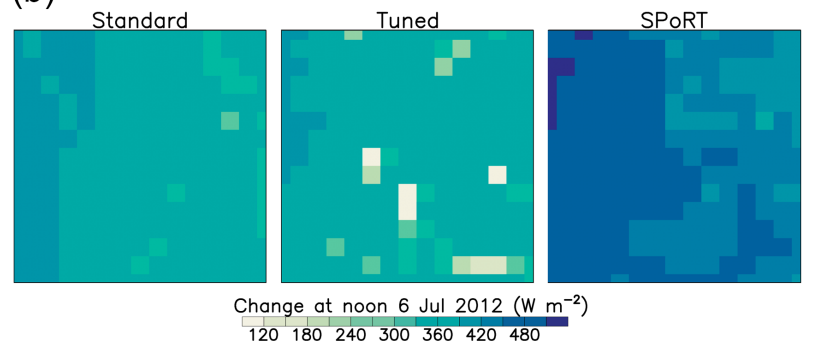

Figure 6. (a) Domain average difference (i.e., each irrigation run minus Control) in latent heat flux for three diurnal cycles in July 2012 (b). Difference in latent heat flux at noon on 6 July 2012.

deeper roots), low soil moisture (from lack of precipitation), and high irrigation intensity.

\subsection{Model performance}

\subsubsection{Evaluation of irrigation amounts and CRNP soil moisture evaluation}

The simulation of irrigation amounts and timing as well as impacts on soil moisture are evaluated for the growing season of 2014 using field observations near Waco, Nebraska, as described in Sect. 3.2. Figure 7 shows daily irrigation and rainfall amounts (right axis), as well as the volumetric soil water content (left axis) from the in situ CRNP (solid black line) and all model simulations (green lines) at the rain-fed and irrigated maize sites. The York AWDN precipitation data confirm that 2014 was a relatively wet growing season, as was originally noted in the examination of Fig. 5b. The soil at the rain-fed site gradually dries out between 15 July and 5 August which is the only consistent rain-free period of the summer (Fig. 7a). The dry-down timing is simulated well in the Control and Tuned simulations, as irrigation is not included in Control and is prohibited at the rain-fed site in Tuned, as defined by the edited irrigation intensity map (i.e., $0 \%$ for this grid cell). In contrast, the Standard and SPoRT simulations consider the rain-fed grid cell to be $100 \%$ irrigated, as given by the GRIPC dataset, and as a result, both runs incorrectly trigger irrigation at this site, increasing SM during the dry-down period. 

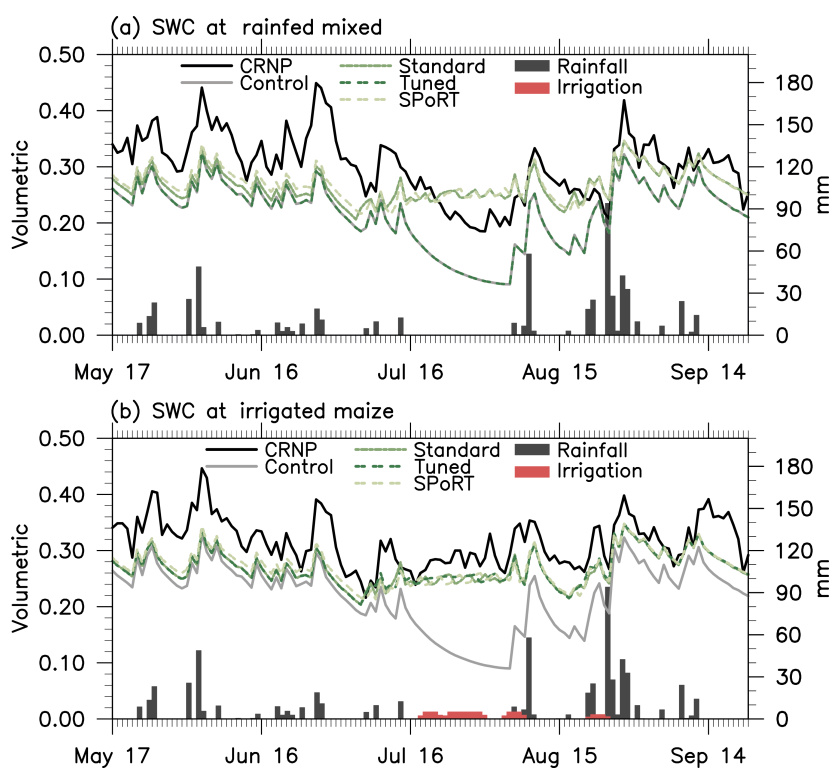

Figure 7. Volumetric soil water content (left axis) at the rain-fed (a) and irrigated maize (b) sites. The black solid line shows observations from the CRNP probe; the gray and green lines show the LIS Control and irrigation simulations, respectively. Dark gray bars show accumulated daily precipitation from the Automated Daily Weather Network in York, Nebraska, and pink bars show the accumulated irrigation amount at the irrigated maize and soybean sites (right axis).

At the irrigated maize site, irrigation is applied during the rain-free period in mid-July and early August and during a second, shorter stint late in August (red bars, Fig. 7b). The model simulations generally overestimate the amount of irrigation water at the irrigated site, applying an average of 8$15 \mathrm{~mm} \mathrm{day}^{-1}$ (not shown), while the observations show that the irrigated field generally received $5 \mathrm{~mm}$ day $^{-1}$. In contrast to the rain-fed site, the CRNP observations show SM increases or remains steady in mid-July through early August due to irrigation by the farmer at the maize site.

The triggering of irrigation during the dry-down period is simulated well by the model as evidenced by the soil moisture differences between the Control and irrigated runs at the irrigated maize site (i.e., dry-down versus steady SM levels, respectively). The SM given by the irrigated simulations matches the CRNP observations more closely than Control during the dry-down period. This indicates that the combination of NLDAS- 2 forcing and the triggering thresholds is sufficient to activate irrigation during rain-free periods, even in a wet year. Each irrigated LIS simulation applies enough irrigation water to maintain the SM levels, with small but inconsequential variations in the day-to-day variability.

The soil water content observations are consistently greater than that of the model at both the rain-fed and irrigated sites. However, it is common for soil moisture probes, other observations (e.g., satellite), and land surface models to

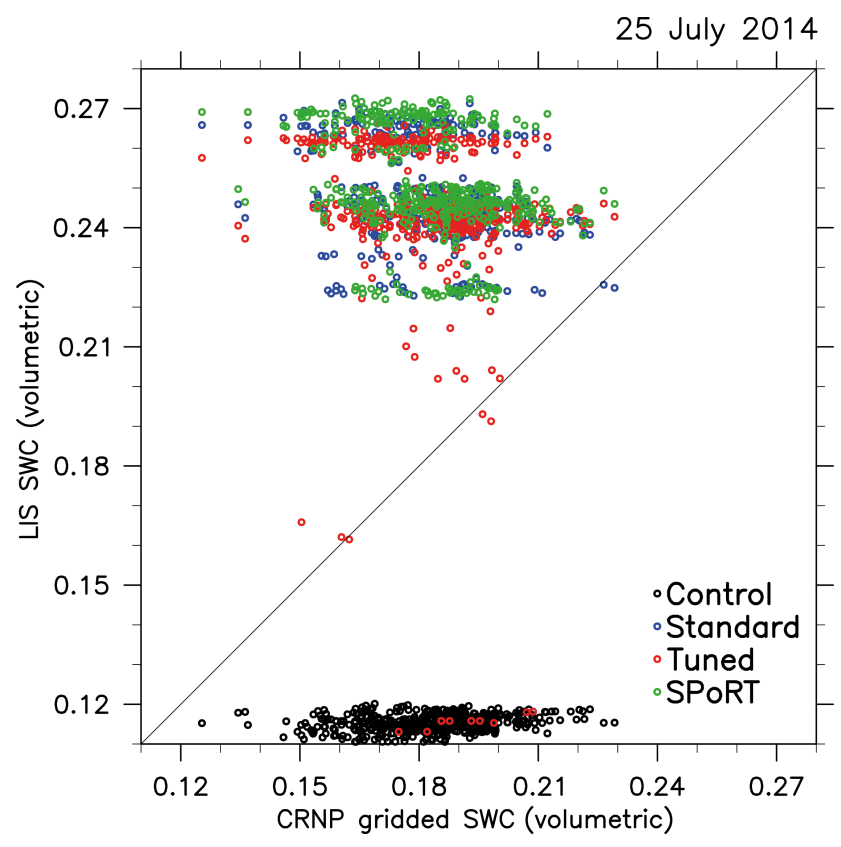

Figure 8. Scatter plot of the grid-cell soil water content given by the CRNP gridded soil moisture product as compared to the LIS simulations.

exhibit different soil moisture climatologies that are largely a function of different representative depths of the soil (e.g., in model versus CRNP). The spikes in soil moisture shown in the probe observations are represented well by the model, once again indicating the accuracy of the NLDAS-2 meteorological forcing data, even at this local scale. Overall, these results show that the irrigation scheme simulates well the irrigated versus rain-fed soil moisture differences when the irrigation location is specified properly by the irrigation intensity dataset (in this case, the Tuned simulation).

\subsubsection{Evaluation with CRNP gridded product}

The LIS-simulated soil moisture variability in time and space is evaluated against the CRNP gridded soil moisture product, described in Sect. 3.2. The spatial variability is assessed first with a histogram generated using all grid-cell soil moisture values from the LIS simulations and the modified CRNP product aggregated at 04:00, 12:00, and 20:00 UTC on 25 July 2014 (Fig. 8). Next, the temporal variability is assessed using a cumulative distribution function (CDF) of the domain averaged soil moisture values from 5 May to 22 September at $8 \mathrm{~h}$ intervals (Fig. 9).

Figure 8 shows that the Control simulation does not match the observations in magnitude or variability, instead showing uniformly dry soil across the domain (e.g., range of 0.01 versus more than 0.1 observations). The spatial variability is increased in the irrigated simulations, but these runs exhibit jumps between clusters of values as a result of irrigation triggering and dry down across the domain. The different levels 
(a)

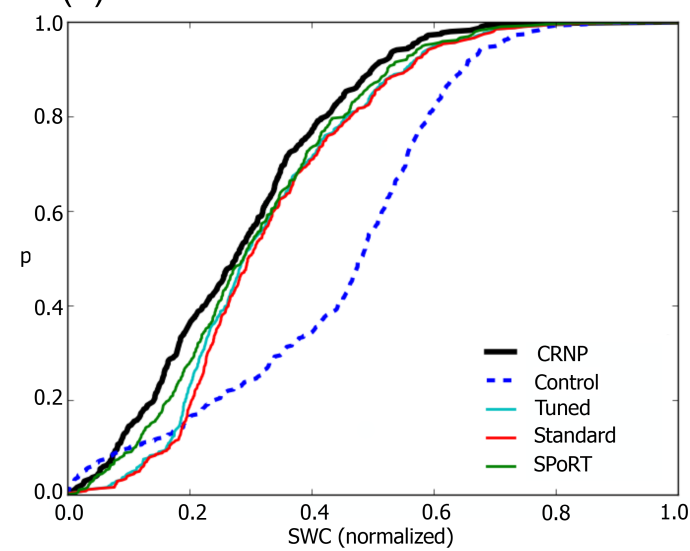

(b)

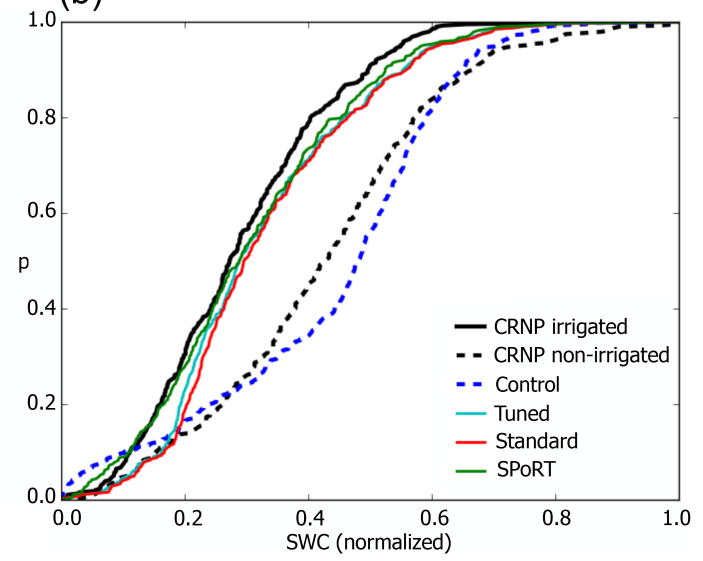

Figure 9. CDF of normalized (a) domain averaged and (b) irrigated/non-irrigated spatial average soil water content (SWC) values from 5 May to 16 September from the COSMOS observational product (black) and the model simulations (colors).

of clustering shown by the irrigated simulations are a result of the input parameter datasets, as triggering and timing are dependent on these datasets. Although the Control simulation is too dry, the irrigation overcompensates and increases the soil moisture to levels beyond those shown in the gridded observations. These results suggest that the model, even with the irrigation algorithm turned on, is not able to accurately simulate the small-scale (i.e., field-scale) heterogeneity in soil moisture that is present in the CRNP data. The heterogeneity at this timescale and space scale results from the fact that center pivot irrigation systems typically take about 3 days to complete one rotation, so that the most recently treated slice of the field is always wetter than the rest. Further, individual decisions made by farmers on and immediately preceding this date (NASS, 2014) are not captured by the strict soil moisture deficit-based rules imposed by the irrigation algorithm, nor by the uniform land cover and soil texture, soil type, and slowly varying GVF datasets at $1 \mathrm{~km}$ resolution.
In contrast, the bulk temporal variability in soil moisture in both irrigated and non-irrigated areas during the growing season is simulated well by the model (Fig. 9). The CDF shows that the model matches the CRNP distribution more closely when the irrigation algorithm is turned on (Fig. 9a). Furthermore, when irrigated and non-irrigated areas are averaged separately, the irrigated and Control simulations match well the distribution of irrigated and non-irrigated areas, respectively (Fig. 9b). These results suggest that if this domain were one grid cell in a larger, coarser-resolution domain (e.g., $15 \mathrm{~km}$ spatial resolution), the variation in the grid-cell soil moisture (given here by the domain average) over the growing season would be representative of observations. That is, the heterogeneity and smaller-scale processes resolved in the high-resolution domain, though unable to reproduce specific field-scale behavior, appropriately scale up to coarser resolution. At coarser time and space resolutions, the decisions made by individual farmers become less important, in favor of the larger-scale features (e.g., timing of precipitation during the growing season) that influence and drive the collective behavior of human practices in this region.

\section{Discussion}

Although the responses of the modeled states and fluxes to simulated irrigation will vary depending on the LSM and irrigation scheme used, the results of this study are broadly relevant to irrigation modeling development as a whole. In particular, this study demonstrates the importance of supplying a land surface model with high-quality input datasets. Of primary importance are the datasets that control irrigation triggering (e.g., land cover, meteorological forcing, irrigated area), as the details of irrigation application are relevant only after irrigation is triggered at the proper locations and at the correct times during the season. Once reasonable timing and placement have been established, the datasets that regulate the amount of water applied (e.g., irrigation intensity, root depth, GVF) become important. These datasets may require a certain degree of customization, depending on the available information about irrigation practices, water district regulations, and land use in the study area, to ensure an appropriate amount of water is applied.

For this small domain, the NLDAS-2 precipitation proved to be sufficiently accurate, matching well that given by the nearby York, Nebraska, AWDN. However, for other regions, reliable meteorological forcing may not be available. To further explore the impact of the forcing precipitation on the irrigation triggering, an additional simulation was completed that is equivalent to the Standard irrigation run in all aspects (e.g., GRIPC irrigation intensity, climatological GVF) except that the Global Data Assimilation System (GDAS) meteorological forcing is used rather than NLDAS-2. In contrast to NLDAS-2, GDAS is coarser resolution $\left(1 / 4^{\circ}\right)$ and does not include rain-gauge corrections. Results show that GDAS 
supplied a greater amount of total of precipitation in May through July 2014, creating a wetter soil column and prohibiting irrigation triggering in mid-to-late July, in contrast to observations and the other irrigation simulations. As a result, the soil moisture dynamics of the GDAS simulation at the maize site differ substantially from the CRNP observations and the NLDAS-2-forced simulations. These results underscore the need for highest quality datasets available for the area of interest, which for this region and time frame was NLDAS-2.

The root systems of crops generally mirror the vegetative state above ground (i.e., GVF), and as such, the model represents root growth by scaling the maximum root depth by the GVF (Ozdogan et al., 2010) and applying a proportional amount of irrigation water. Although the crop type is uniform maize for the limited domain, as given by the UMD crop dataset, Franz et al. (2015) shows a mix of maize and soybeans in the study area. An additional run was completed in which a tuned crop type map was supplied to the model to distinguish between maize and soybean grid cells based on the land use map of Franz et al. (2015) and the maximum root depth was altered to be $1.2 \mathrm{~m}$ for maize and $1 \mathrm{~m}$ for soybean. The results of this analysis showed little difference between this simulation and the others, indicating that the model is insensitive to small changes (up to $20 \%$ ) in the maximum root depth. However, land surface models that have a more complex treatment of crops, study areas with greater heterogeneity of crop types, or experiments that replace a particular crop with one that has a vastly deeper root system are examples beyond the scope of this study that could potentially result in a greater sensitivity of the model results to crop root depth.

The method for determining the start and end of the growing season, based on the $40 \%$ annual range in climatological GVF, proved to be reliable for this study area and climate. However, in arid or semi-arid regions, the $40 \%$ threshold applied to a small annual range in GVF can result in a yearround irrigation season that may not be representative of regional irrigation practices. Thus, where the annual range in GVF is small (e.g., southern California), more tailoring may be needed to ensure that irrigation occurs only during the local irrigation season.

Recent work by Decker et al. (2017) shows that atmospheric feedbacks can reduce the irrigation demand simulated by a land surface model. That is, a coupled model configuration allows the atmosphere to respond to the irrigation application, moistening the near-surface area, and reducing the need for additional irrigation as compared to the same model run uncoupled. A limitation of the work presented here is therefore the lack of the atmospheric feedback in the uncoupled configuration. However, the Decker et al. (2017) results indicate that a coupled configuration would likely reduce irrigation amounts simulated by the model. As the irrigation demand was greater in the model than in the humanpractice observations, the coupled atmosphere has the poten- tial to reduce irrigation amounts to be more in line with those observed.

This study shows model sensitivity to the irrigation intensity dataset in terms of where and how much irrigation water is applied. Historically, the Global Map of Irrigated Areas (GMIA; Döll and Siebert, 1999) has been the most widely used irrigation dataset in irrigation modeling studies (Bonfils and Lobell, 2007; Boucher et al., 2004; Guimberteau et al., 2012, among many others) as it was the first reliable global irrigation map, making use of cartographic and FAO statistics. However, progress in satellite remote sensing and ease of access to required datasets will likely result in a growing number of options for irrigation intensity datasets in the coming years (e.g., Siebert et al., 2015). As such, the results of this study, detailing the potential effects of choice of irrigation intensity dataset on irrigation amounts, will likely become more relevant with the expansion in choices of irrigationrelated datasets.

\section{Conclusions}

This study provided an assessment of the sprinkler irrigation physics and model sensitivity to irrigation intensity and GVF datasets in a LSM framework and evaluated the results with novel point and gridded soil moisture observations. As expected, model results show that irrigation increases soil moisture and latent heat flux and decreases sensible heat flux. Differences between experiments with different GVF and irrigation intensity parameters are small at large and interannual scales but become more substantial at small and subseasonal scales. The irrigation scheme uses GVF as a proxy for plant maturity and scales the amount of water applied accordingly to represent differences in irrigation scheduling based on growth stage. This behavior and the impacts of irrigation on soil moisture and fluxes are physically consistent with expectations of irrigation effects on the land surface.

The evaluation with CRNP observations revealed both limitations and strengths of the irrigation algorithm. Fieldscale heterogeneity resulting from the slow rotation rates of center pivot irrigation systems and the individual actions of farmers is not captured by the model. Also, the amount of irrigation applied by the model exceeds that applied at the two irrigated fields. However, the timing of irrigation during the growing season (i.e., late July to early August), which coincided with a stretch of limited rainfall, is simulated well by the scheme. Additionally, the fine-scale processes resolved in the small domain appropriately scale up in time and space, indicating the scheme could be used reliably at coarser resolution (e.g., $15 \mathrm{~km}$ ) in this region. The model skill is due in large part to the accuracy of NLDAS-2 meteorological forcing, land cover, and irrigation intensity datasets, which are all critical to reproducing the seasonal timing and location of irrigation triggering. Overall, these results underscore 
the importance of supplying a LSM with high-quality input datasets.

This study has also shown that CRNP distributed soil moisture data can be valuable in LSM and irrigation parameterization evaluation. The CRNP observations provide information about the impact of irrigation on the spatial and temporal variability of soil moisture and could possibly be used to help identify where and when irrigation occurs. Irrigation timing information is particularly valuable at the scales of this study and larger, where accurate reporting data are not always available. The USDA Census of Agriculture contains some of the most detailed information on the state of agriculture in the US, including estimates of irrigated acreage, irrigation method, and crop cultivated. However, the census occurs only once every 5 years and lacks irrigation timing information. CRNP soil moisture could potentially be used to fill those data gaps. It is logical that satellite-based soil moisture and evapotranspiration would also help in that respect, although a recent study cast doubt on the utility of the former (Kumar et al., 2015).

The flexibility of the LIS framework, and in particular the ability for the user to choose the irrigation scheme, parameters, and model of choice, makes LIS a premier framework for irrigation studies. However, the general conclusions of this study, as they pertain to irrigation scheme impacts and sensitivity to dataset changes, are applicable to irrigation modeling more broadly. The continued evaluation and improvement of irrigation parameterizations, as discussed here, are an important step towards better understanding human influences on the water cycle and the impacts of such activities in a changing climate.

Data availability. Fixed and mobile cosmic-ray neutron probe data are available in Franz et al. (2015) or by request from Trenton Franz.

\section{The Supplement related to this article is available online at https://doi.org/10.5194/hess-21-2953-2017- supplement.}

Competing interests. The authors declare that they have no conflict of interest.

Acknowledgements. T. E. Franz would like to thank the Daugherty Water for Food Global Institute and the Cold Regions Research and Engineering Laboratory through the Great Plains CESU for financial support. T. E. Franz would like to thank Chase Johnson, Romohr Farms, and the residents of Waco, NE, for access to field sites, data, and patience for slow rover driving. This work was partially supported by the NASA Earth and Space Science Fellowship.
Edited by: M. McCabe

Reviewed by: O. Lopez and three anonymous referees

\section{References}

Adegoke, J. O., Pielke, R., and Carleton, A. M.: Observational and modeling studies of the impacts of agriculturerelated land use change on planetary boundary layer processes in the central U.S., Agr. Forest Meteorol., 142, 203-215, https://doi.org/10.1016/j.agrformet.2006.07.013, 2007.

Alter, R. E., Im, E.-S., and Eltahir, E. A. B.: Rainfall consistently enhanced around the Gezira Scheme in East Africa due to irrigation, Nat. Geosci., 8, 763-767, https://doi.org/10.1038/ngeo2514, 2015.

Bonfils, C. and Lobell, D.: Empirical evidence for a recent slowdown in irrigation-induced cooling, P. Natl. Acad. Sci. USA, 104, 13582-13587, https://doi.org/10.1073/pnas.0700144104, 2007.

Boucher, O., Myhre, G., and Myhre, A.: Direct human influence of irrigation on atmospheric water vapour and climate, Clim. Dynam., 22, 597-603, https://doi.org/10.1007/s00382-004-0402-4, 2004.

Case, J. L., Lafontaine, F. J., Bell, J. R., Jedlovec, G. J., Kumar, S. V., and Peters-Lidard, C. D.: A real-time MODIS vegetation product for land surface and numerical weather prediction models, IEEE T. Geosci. Remote Sens., 52, 1772-1786, https://doi.org/10.1109/TGRS.2013.2255059, 2014.

Chen, F., Manning, K. W., LeMone, M. A., Trier, S. B., Alfieri, J. G., Roberts, R., Tewari, M., Niyogi, D., Horst, T. W., Oncley, S. P., Basara, J. B., and Blanken, P. D.: Description and evaluation of the characteristics of the NCAR high-resolution land data assimilation system, J. Appl. Meteorol. Climatol., 46, 694-713, https://doi.org/10.1175/JAM2463.1, 2007.

Chrisman, B. and Zreda, M.: Quantifying mesoscale soil moisture with the cosmic-ray rover, Hydrol. Earth Syst. Sci., 17, 50975108, https://doi.org/10.5194/hess-17-5097-2013, 2013.

Decker, M., Ma, S., and Pitman, A.: Local land atmosphere feedbacks limit irrigation demand, Environ. Res. Lett., 12, 054003, https://doi.org/10.1088/1748-9326/aa65a6, 2017.

Desilets, D. and Zreda, M.: Footprint diameter for a cosmic-ray soil moisture probe: Theory and Monte Carlo simulations, Water Resour. Res., 49, 3566-3575, https://doi.org/10.1002/wrcr.20187, 2013.

de Vrese, P., Hagemann, S., Claussen, M.: Asian irrigation, African rain: Remote impacts of irrigation, Geophys. Res. Lett., 43, 3737-3745, https://doi.org/10.1002/2016GL068146, 2016.

Döll, P. and Siebert, S.: A digital global map of irrgated areas, Report A9901, Center for Environmental Systems Research, University of Kassel, Kurt Wolters Strasse 3, 34109 Kassel, Germany, 1999.

Dong, J. N., Ochsner, T. E., Zreda, M., Cosh, M. H., and Zou, C. B.: Calibration and validation of the COSMOS rover for surface soil moisture measurement, Vadose Zone J., 13, vzj2013.08.0148, https://doi.org/10.2136/vzj2013.08.0148, 2014.

Douglas, E. M., Niyogi, D., Frolking, S., Yeluripati, J. B., Pielke, R. A., Niyogi, N., Vörösmarty, C. J., and Mohanty, U. C.: Changes in moisture and energy fluxes due to agricultural land use and irrigation in the Indian Monsoon Belt, Geophys. Res. Lett., 33, L14403, https://doi.org/10.1029/2006GL026550, 2006. 
Entin, J. K., Robock, A., Vinnikov, K. Y., Hollinger, S. E., Liu, S., and Namkhai, A.: Temporal and spatial scales of observed soil moisture variations in the extratropics, J. Geophys. Res., 105, 865-877, https://doi.org/10.1029/2000JD900051, 2000.

Evans, J. P. and Zaitchik, B. F.: Modeling the large-scale water balance impact of different irrigation systems, Water Resour. Res., 44, W08448, https://doi.org/10.1029/2007WR006671, 2008.

FAO: Water withdrawal by sector, Aquastat database report, available at: http://www.fao.org/nr/aquastat (last access: 15 June 2017), 2014.

Franz, T. E., Zreda, M., Ferre, T. P. A., Rosolem, R., Zweck, C., Stillman, S., Zeng, X., and Shuttleworth, W. J.: Measurement depth of the cosmic ray soil moisture probe affected by hydrogen from various sources, Water Resour. Res., 48, 1-9, https://doi.org/10.1029/2012WR011871, 2012.

Franz, T. E., Wang, T., Avery, W., Finkenbiner, C., and Brocca, L.: Combined analysis of soil moisture measurements from roving and fixed cosmic ray neutron probes for multiscale real-time monitoring, Geophys. Res. Lett., 42, 1-8, https://doi.org/10.1002/2015GL063963, 2015.

Guimberteau, M., Laval, K., Perrier, A., and Polcher, J.: Global effect of irrigation and its impact on the onset of the Indian summer monsoon, Clim. Dynam., 39, 1329, https://doi.org/10.1007/s00382-011-1252-5, 2012.

Harding, K. J., Twine, T. E., and Lu, Y.: Effects of dynamic crop growth on the simulated precipitation response to irrigation, Earth Interact., 19, 1-31, https://doi.org/10.1175/EI-D-15$0030.1,2015$.

Harding, K. J. and Snyder, P. K.: Modeling the atmospheric response to irrigation in the Great Plains. Part I: General impacts on precipitation and the energy Budget, J. Hydrometeorol., 13, 1667-1686, https://doi.org/10.1175/JHM-D-11-098.1, 2012a.

Harding, K. J. and Snyder, P. K.: Modeling the atmospheric response to irrigation in the Great Plains. Part II: The precipitation of irrigated Water and changes in precipitation recycling, J. Hydrometeorol., 13, 1687-1703, https://doi.org/10.1175/JHMD-11-099.1, 2012b.

Kanamaru, H. and Kanamitsu, M.: Model diagnosis of nighttime minimum temperature warming during summer due to irrigation in the California Central Valley, J. Hydrometeorol., 9, 10611072, https://doi.org/10.1175/2008JHM967.1, 2008.

Kohli, M., Schron, M., Zreda, M., Schmidt, U., Dietrich, P., and Zacharias, S.: Footprint characteristics revised for field-scale soil moisture monitoring with cosmic-ray neutrons, Water Resour. Res., 51, 5772-5790, https://doi.org/10.1002/2015wr017169, 2015.

Kueppers, L. M. and Snyder, M. A.: Influence of irrigated agriculture on diurnal surface energy and water fluxes, surface climate, and atmospheric circulation in California, Clim. Dynam., 38, 1017-1029, https://doi.org/10.1007/s00382-011-1123-0, 2011.

Kueppers, L. M., Snyder, M. A., and Sloan, L. C.: Irrigation cooling effect: Regional climate forcing by land-use change, Geophys. Res. Lett., 34, L03703, https://doi.org/10.1029/2006GL028679, 2007.

Kueppers, L. M., Snyder, M. A., Sloan, L. C., Cayan, D., Jin, J., Kanamaru, H., Kanamitsu, M., Miller, N. L., Tyree, M., Du, H., and Weare, B.: Seasonal temperature responses to land-use change in the western United States, Global Planet. Change, 60, 250-264, https://doi.org/10.1016/j.gloplacha.2007.03.005, 2008.
Kumar, S. V, Peters-lidard, C. D., Tian, Y., Houser, P. R., Geiger, J., Olden, S., Lighty, L., Eastman, J. L., Doty, B., Dirmeyer, P., Adams, J., Mitchell, K., Wood, E. F., and Sheffield, J.: Land information system?: An interoperable framework for high resolution land surface modeling, Environ. Model. Softw., 21, 14021415, https://doi.org/10.1016/j.envsoft.2005.07.004, 2006.

Kumar, S. V., Peters-Lidard, C. D., Santanello, J. A., Reichle, R. H., Draper, C. S., Koster, R. D., Nearing, G., and Jasinski, M. F.: Evaluating the utility of satellite soil moisture retrievals over irrigated areas and the ability of land data assimilation methods to correct for unmodeled processes, Hydrol. Earth Syst. Sci., 19, 4463-4478, https://doi.org/10.5194/hess-19-4463-2015, 2015.

Kustu, D., Fan, Y., and Rodell, M.: Possible link between irrigation in the US High Plains and increased summer streamflow in the Midwest, Wat. Resour. Res., 47, W03522, https://doi.org/10.1029/2010WR010046, 2011.

Lawston, P. M., Santanello, J. A., Zaitchik, B. F., and Rodell, M.: Impact of irrigation methods on land surface model spinup and initialization of WRF forecasts, J. Hydrometeorol., 16, 11351154, https://doi.org/10.1175/JHM-D-14-0203.1, 2015.

Leng, G., Huang, M., Tang, Q., Sacks, W. J., Huimin, L., Leung, and L. R.: Modeling the effects of irrigation on land surface fluxes and states over the conterminous United States: Sensitivity to input data and model parameters, J. Geophys. Res., 118, 97899803, https://doi.org/10.1002/jgrd.50792, 2013.

Leng, G., Huang, M., Tang, Q., Gao, H., Leung, L. R.: Modeling the effects of groundwater-fed irrigation on terrestrial hydrology over the conterminous United States, J. Hydrometeorol., 15, 957-972, https://doi.org/10.1175/JHM-D-13-049.1, 2014.

Lobell, D., Bala, G., Mirin, A., Phillips, T., Maxwell, R., and Rotman, D.: Regional differences in the influence of irrigation on climate, J. Clim., 22, 2248-2255, https://doi.org/10.1175/2008JCLI2703.1, 2009.

Lu, Y., Jin, J., and Kueppers, L. M.: Crop growth and irrigation interact to influence surface fluxes in a regional climate-cropland model (WRF3.3-CLM4crop), Clim. Dynam., 45, 3347-3363, https://doi.org/10.1007/s00382-015-2543-z, 2015.

Molden, D.: Water for Food, Water for Life: A comprehensive assessment of water management in agriculture, Earthscane/International Water Management Institute, London/Colombo, Sri Lanka, 2007.

NASS: 2012 census of agriculture: Farm and ranch irrigation survey, (3) Special studies, Part 1, Rep. AC-12-ss-1, National Agricultural Statistics Service, USDA, 266 pp., 2014.

Ozdogan, M., Rodell, M., Beaudoing, H. K., and Toll, D. L.: Simulating the effects of irrigation over the United States in a land surface model based on satellitederived agricultural data, J. Hydrometeorol., 11, 171-184, https://doi.org/10.1175/2009JHM1116.1, 2010.

Pei, L., Moore, N., Zhong, S., Kendall, A. D., Hyndman, D. W., and Gao, Z.: Effects of irrigation on the summer climate over the United States, J. Clim., 29, 3541-3558, https://doi.org/10.1175/JCLI-D-15-0337.1, 2016.

Pervez, M. S. and Brown, J. F.: Mapping irrigated lands at 250-m scale by merging MODIS data and national agricultural statistics, Remote Sens., 2, 2388-2412, https://doi.org/10.3390/rs2102388, 2010.

Peters-Lidard, C. D., Kemp, E. M., Matsui, T., Santanello Jr., J. A., Kumar, S. V. , Jacob, J. P., Clune, T., Tao, W-K., Chin, 
M., Hou, A., Case, J. L., Kim, D., Kim, K-M., Lau, W., Liu, Y., Shi, J., Starr, D., Tan, Q., Tao, Z., Zaitchik, B. F., Zavodsky, B., Zhang, S. Q., and Zupanski, M.: Integrated modeling of aerosol, cloud, precipitation and land processes at satellite-resolved scales, Environ. Modell. Softw., 67, 149-159, https://doi.org/10.1016/j.envsoft.2015.01.007, 2015.

Pokhrel, Y., Hanasaki, N., Koirala, S., Cho, J., Yeh, P. J.-F., Kim, H., Kanae, S., and Oki, T.: Incorporating anthropogenic water regulation modules into a land surface model, J. Hydrometeorol., 13, 255-269, https://doi.org/10.1175/JHM-D-11-013.1, 2012.

Puma, M. J. and Cook, B. I.: Effects of irrigation on global climate during the 20th century, J. Geophys. Res., 115, D16120, https://doi.org/10.1029/2010JD014122, 2010.

Qian, Y., Huang, M., Yang, B., and Berg, L. K.: A modeling study of irrigation effects on surface fluxes and land-air-cloud interactions in the southern Great Plains, J. Hydrometeorol., 14, 700721, https://doi.org/10.1175/JHM-D-12-0134.1, 2013.

Quiring, S. M., Ford, T. W., Wang, J. K., Khong, A., Harris, E., Lindgren, T., Goldberg, D. W., and Li, Z.: The North American soil moisture database: Development and Applications, Bull. Amer. Meteorol. Soc., 97, 1441-1459, https://doi.org/10.1175/BAMS-D-13-00263.1, 2016.

Salmon, J. M., Friedl, M. A., Frolking, S., Wisser, D., and Douglas, E. M.: Global rain-fed, irrigated, and paddy croplands: A new high resolution map derived from remote sensing, crop inventories and climate data, Int. J. Appl. Earth Obs. Geoinf., 38, 321-334, https://doi.org/10.1016/j.jag.2015.01.014, 2015.

Santanello, J. A., Peters-Lidard, C. D., and Kumar, S. V.: Diagnosing the sensitivity of local land-atmosphere coupling via the soil moisture-boundary layer interaction, J. Hydrometeorol., 12, 766-786, https://doi.org/10.1175/JHM-D-10-05014.1, 2011.

Schultz, B., Thatte, C. D., and Labhsetwar, V. K.: Irrigation and drainage: Main contributors to global food production, Irrig. Drain., 54, 263-278, https://doi.org/10.1002/ird.170, 2005.

Siebert, S., Kummu, M., Porkka, M., Döll, P., Ramankutty, N., and Scanlon, B. R.: A global data set of the extent of irrigated land from 1900 to 2005, Hydrol. Earth Syst. Sci., 19, 1521-1545, https://doi.org/10.5194/hess-19-1521-2015, 2015.

Skamarock, W. C., Klemp, J. B., Dudhia, J., Gill, D. O., Barker, D. M., Wang, W., and Powers, J. G.: A description of the advanced research WRF version 2. NCAR Tech. Note NCAR/TN4681STR, 88, https://doi.org/10.5065/D6DZ069T, 2005.

Sorooshian, S., Li, J., Hsu, K., and Gao, X.: How significant is the impact of irrigation on the local hydroclimate in California's Central Valley? Comparison of model results with ground and remote-sensing data, J. Geophys. Res., 116, D06102, https://doi.org/10.1029/2010JD014775, 2011.
Sorooshian, S., Li, J., Hsu, K., and Gao, X.: Influence of irrigation schemes used in regional climate models on evapotranspiration estimation: Results and comparative studies from California's Central Valley agricultural regions, J. Geophys. Res., 117, D06107, https://doi.org/10.1029/2011JD016978, 2012.

Trenberth, K. E. and Asrar, G. R.: Challenges and opportunities in water cycle research: WCRP Contributions, Surv. Geophys., 35, 515-532, https://doi.org/10.1007/s10712-012-9214-y, 2014.

Tuinenburg, O. A., Hutjes, R. W. A., Stacke, T., Wiltshire, A., and Lucas-Picher, P.: Effects of irrigation in India on the atmospheric water budget, J. Hydrometeorol., 15, 1028-1050, https://doi.org/10.1175/JHM-D-13-078.1, 2014.

Vahmani, P. and Hogue, T. S.: Incorporating an urban irrigation module into the Noah land surface model coupled with an urban canopy model, J. Hydrometeorol., 15, 1440-1456, https://doi.org/10.1175/JHM-D-13-0121.1, 2014.

van Oevelen, P.: Water for food baskets of the world, GEWEX News, 26, 2, 2016.

Visvalingam, M. and Tandy, J.D.: The neutron method for measuring soil moisture content - a review, J. Soil Sci., 23, 499-511, https://doi.org/10.1111/j.1365-2389.1972.tb01680.x, 1972.

Xia, Y. L., Mitchell, K., Ek, M., Sheffield, J., Cosgrove, B., Wood, E., Luo, L. F., Alonge, C., Wei, H. L., Meng, J., Livneh, B., Lettenmaier, D., Koren, V., Duan, Q. Y., Mo, K., Fan, Y., and Mocko, D.: Continental-scale water and energy flux analysis and validation for the North American Land Data Assimilation System project phase 2 (NLDAS-2): 1. Intercomparison and application of model products, J. Geophys. Res., 117, D03109, https://doi.org/10.1029/2011jd016048, 2012.

Yilmaz, M. T., Anderson, M. C., Zaitchik, B., Hain, C. R., Crow, W. T., Ozdogan, M., Chun, J. A., and Evans, J.: Comparison of prognostic and diagnostic surface flux modeling approaches over the Nile River basin, Water Resour. Res., 50, 386-408, https://doi.org/10.1002/2013WR014194, 2014.

Zreda, M., Shuttleworth, W. J., Zeng, X., Zweck, C., Desilets, D., Franz, T., and Rosolem, R.: COSMOS: the COsmic-ray Soil Moisture Observing System, Hydrol. Earth Syst. Sci., 16, 40794099, https://doi.org/10.5194/hess-16-4079-2012, 2012. 